\title{
SONGBIRD - an innovative UAS combining the advantages of fixed wing and multi rotor UAS
}

\author{
H.-P. Thamm ${ }^{\text {a }}$, N. Brieger ${ }^{\mathrm{a}}$, K.-P. Neitzke ${ }^{\mathrm{b}}$, M. Meyer ${ }^{\mathrm{a}}$, R. Jansen ${ }^{\mathrm{a}}$, M. Mönninghof ${ }^{\mathrm{a}}$ \\ a IGT Integrated Geo-Technologies GmbH , 10553 Berlin, Germany (hp.thamm, n.brieger, m.meyer, r.jansen, m.moenninghof@gt- \\ technologies.com) \\ ${ }^{\mathrm{b}}$ Hochschule Nordhausen, IAE - Institut für Informatik, Automatisierung und Elektronik, Weinberghof 99734 Nordhausen, \\ Deutschland, (neitzke@hs-nordhausen.de)
}

Commission VI, WG VI/4

KEY WORDS: UAV, VTOL, fixed wing, Wing Copter, resource management, pipeline inspection, cartography

\begin{abstract}
:
This paper describes a family of innovative fixed wing UAS with can vertical take off and land - the SONGBIRD family. With nominal payloads starting from $0.5 \mathrm{~kg}$ they can take off and land safely like a multi-rotor UAV, removing the need for an airstrip for the critical phases of operation. A specially designed flight controller allows stable flight at every point of the transition phase between VTOL and fixed wing mode. Because of this smooth process with a all time stable flight, very expensive payload like hyperspectral sensors or advanced optical cameras can be used. Due to their design all airplanes of the SONGBIRD family have excellent horizontal flight properties, a maximum speed of over $110 \mathrm{~km} / \mathrm{h}$, good gliding properties and long flight times of up to $1 \mathrm{~h}$. Missions were flown in wind speeds up to $18 \mathrm{~m} / \mathrm{s}$. At every time of the flight it is possible to interrupt the mission and hover over a point of interest for detail investigations. The complete flight, including take-off and landing can be performed by autopilot. Designed for daily use in professional environments, SONGBIRDs are built out of glass-fibre and carbon composites for a long service life. For safe operations comprehensive security features are implemented, for example redundant flight controllers and sensors, advanced power management system and mature fail safe procedures. The aircraft can be dismantled into small parts for transportation. SONGBIRDS are available for different pay loads, from $500 \mathrm{~g}$ to $2 \mathrm{~kg}$. The SONGBIRD family are interesting tools combining the advantages of multi-copter and fixed wing UAS.
\end{abstract}

\section{INTRODUCTION}

\subsection{Background}

For many tasks there is a high demand for remote sensed information in a very high spatial resolution (Colomina, Molina, 2014). Due to technical progress within the last years UAV ("unmanned aerial vehicles") proved to be valuable tools to provide this information in the desired temporal and spatial resolution (Pajares, 2015). Many different UAV are now on the market (van Blyenburgh, 2015). In general the UAV can be divided into two major groups.

On the one side there are the multi-copters, which create the lift for take-off and flight active with their propellers. Multi-copters have several advantages. Their flight controllers are mature, so they are easy to fly and take-off, landing as well as autonomous flight is no problem. They do not need a landing strip, which is a big advantage in the field, in forests or in urban environments. But there are disadvantages: Because multi-copters have to create their lift during the complete flight actively, their endurance and their operation speed is restricted. In general they have a flight time between $12 \mathrm{~min}-30 \mathrm{~min}$ which means that they can only cover limited areas (Eisenbeiss, 2009, Cai et al. 2014).

The other group are fixed wing UAV, which have wings like traditional airplanes. A large fraction of the needed lift is created dynamic by the wing so their flight is far more efficient (dependent on the design of the UAV and the wing between 3 time to more than 10 times). They can fly with high speed, are within a wide range independent from wind conditions and can reach long flight times (more than 2 hours are possible) before re-fuelling or changing rechargeable batteries. Therefore fixed wing UAV are able to cover large areas with one flight
(Grundlach, 2012) But they have disadvantages: For landing they need a suitable air strip which can be a problem in some areas. As well the comparatively high landing speed makes them vulnerable for getting damaged during landing. This can damage the payload as well, which is not acceptable especially with expensive payloads. For take-off an air strip is needed or the fixed wing UAV must be thrown. This needs special skills or equipment and the UAV they can be damaged if not launched properly (Leomar et al. 2006).

\subsection{Approaches to overcome the disadvantages of the fixed wing UAV}

There have been several attempts to overcome the disadvantages of the fixed wing UAV.

To prevent the fixed wing UAV from being damaged during landing in some UAV a parachute is employed. (Wada et al., 2015, http://aeromao.com/) This has the advantage that the UAV comes down with a low descending speed, which reduces the risk of damages. But this method has disadvantages. As soon as the UAV has released the parachute it is not possible to control the flight any more and the vehicle is vulnerable against wind. Some UAV estimate the wind direction and speed before releasing the parachute to make sure that the UAV on the parachute comes down at the desired landing spot (Wyllie, 2001, Sibilski et al. 2012)

But if there are changes in wind speed or wind direction during the descent, the location where the UAV comes down can diverge from the planned landing point. Under strong wind conditions there is the risk that after landing the UAV, as long as the parachute is still attached at the body of the UAV, it can be dragged over ground if the wind grasps the parachute (Eng et 
al. 2010). Finally the packing procedure which has to be done before flight can be time intensive and a be a source of error. A number of fixed wing UAV are landing in a net (Kim et al. 2013). This has the following disadvantages: A large net must be carried to the operation site and must be assembled properly. Sometimes the UAV misses the net, or it gets damaged when crashing in the net or falling down from the net after landing.

This unsatisfying situation triggers the development of UAV which combine the advantages of fixed wing UAV (long endurance, high operation speed, wind independency, large areas which can be covered) with the advantages of the multicopter (easy and safe start and landing, possibility to hover over an area of interest).

One approach is the family of tail-sitter like the Quadshot (Ferell et al. 2013) the Atmos (Hulsman et al. 2014) or the VertiKul (Hochstenbach, Notteboom, 2014, figure 1). The whole UAV is a wing with at least four engines and propellers. For the take-off it stands vertical (tail-sitter). After having taken off vertically the wing turns in a horizontal position and can fly like a fixed wing UAV. For landing the whole vehicle again turns into a vertical position and comes down vertically.
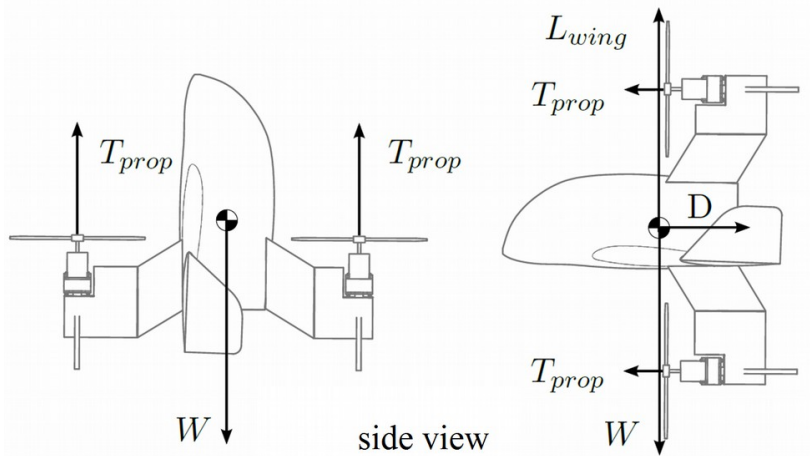

Figure 1. Principle of the VTOL tail-sitter VertiKul. After

(Hochstenbach, Notteboom, 2014) slightly modified.

This system has the advantage that it is mechanically simple; it just needs some engines an appropriate flight controller (if choosing for or more there are good flight controllers available which can be adapted), and has no moveable parts. The start and landing can be a problem under high wind conditions, because the wing faces the wind with the full depth. Standard fixed wing UAV can land against the wind and the wings face the wind with the leading edge.

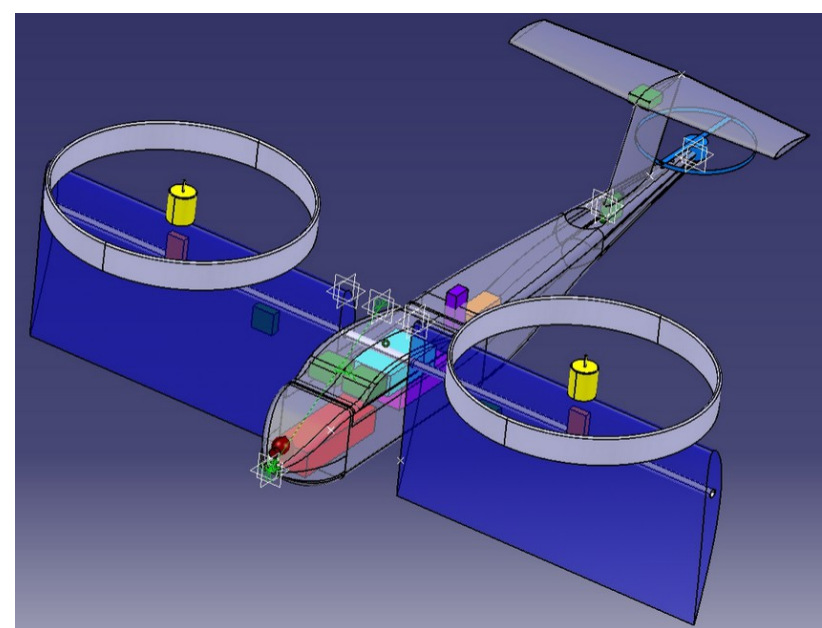

Figure 2. Principle of the tilt wing UAV as described in Holsten et al. (2012), Image taken from Hartmann, Martin (2013)
Another approach to realise vertical start and landing is the tilt wing, figure 2 (Holsten et al., 2011, Hartman, Martin, 2014). For horizontal flight the wing is in a horizontal position, while for take-off and landing the whole wing is tilted to a vertical position. The disadvantage of that system is that the mechanism for moving the wing is quite heavy, so the payload for sensors is reduced.

Similarly to the tail-sitting concept the wing faces the wind with the broad site during take-off and landing which means that high wind speed conditions pose a significant risk to the plane.

\section{THE SONGBIRD}

\subsection{Principle of the SONGBIRD}

To overcome some of the disadvantages of the mentioned systems the SONGBIRD family, a group of vertical take-off and landing fixed wing UAV, was designed. They have the same principle but different wing spans and payloads for different missions. The SONGBIRDS have efficient wing profiles which enables good flight properties. The wing can be parted in 3 parts. In every wing there are two levers. Each of the levers has two engines, a total of four..

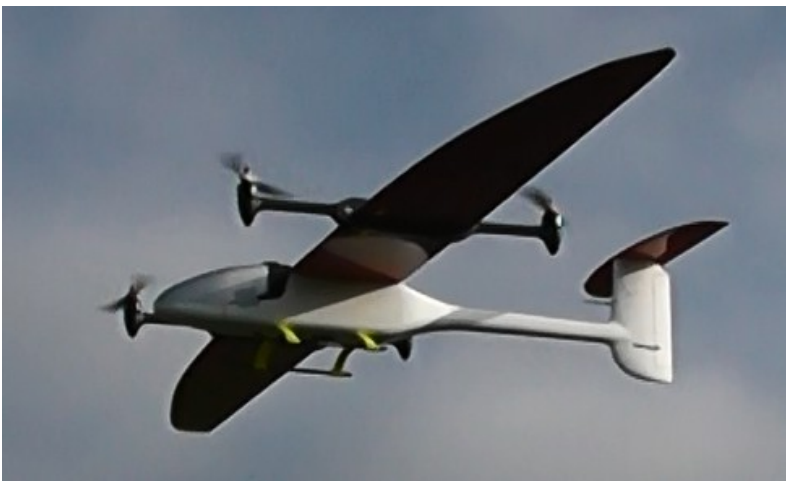

Figure 3. The VTOL fixed wing UAV SONGBIRD $1500 \mathrm{~V} 1$

from the Company IGT. Engines in the vertical position for start, landing and hovering (own image).

For take-off the engines at the levers are facing vertical position (Figure 3). After take-off the levers are moving the engines into a horizontal position (Figure 4). Due to a specially designed flight controller the transition phase is completely stable in all lever angles. It is possible to choose every speed which is desired between $0 \mathrm{~m} / \mathrm{s}$ to more than $33 \mathrm{~m} / \mathrm{s}$.

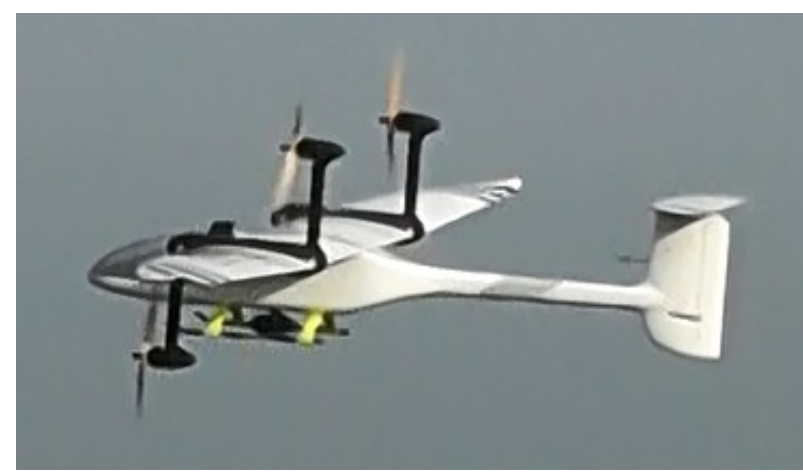

Figure 4. VTOL SONGBIRD $1500 \mathrm{~V} 1$, Engines in the horizontal position horizontal flight (own image).

Due to the concept the forward flight can be interrupted anytime to hover in place over a point of interest. This can be 
advantageous for many applications (search and rescue, inspection of power lines and oil pipelines)

Because only the engines have to be moved, the mechanical parts of the levers are light in comparison with the devices needed to tilt a complete wing. This enables the SONGBRIDS to carry comparatively high pay loads.

The SONGBRIDS carries two flight controllers. The first one stabilizes the aircraft in the hovering, transition and forward flight phases. It was specially developed for safe flight under all circumstances. The second flight controller provides navigation and guidance for autonomous flight and the telecommunication with the ground station. It is planned that for redundancy, in case of a failure of one flight controller the other one can take over.

The complete mission, take off flight and landing, can be performed via autopilot. This has the advantage, that the operation is independent from the skill of the pilots. The auto start and landing software, developed in house, is quite sophisticated. To ensure an safe landing at high wind speed conditions, it is advantageous that the SONGBIRD faces the wind. Therefore the auto landing software estimates during the whole flight the wind speed, the wind direction and their variability. For an efficient use of battery power the autopilot directs the SONGBIRDS towards the landing spot in the gliding mode and determines when the flight modus must be changed between horizontal and vertical flight mode. Therefore the reliable wind estimation has to be used as well. To ensure that during the approach for a landing no flight prohibition zones are violated, alternative routes must be planned as well, even if they are not optimal in regard of wind direction. So the length of the approach for a landing, which is close related to wind speed and wind direction, has to be computed for the different situations.

Due to the optimised wing profiles the SONGBIRDS have good flight properties. The gliding angle is around 30:1. A maximal speed of around $120 \mathrm{~km} / \mathrm{h}$ can be reached, so they can operate even under high wind conditions (up to $18 \mathrm{~m} / \mathrm{s}$ ). The typical operation speed is between $55 \mathrm{~km} / \mathrm{h}$ and $65 \mathrm{~km} / \mathrm{h}$. This ensures a coverage of areas between $4 \mathrm{~km}^{2}$ and $12 \mathrm{~km}^{2}$ within one flight, dependant on the sensors and the desired ground resolution. In the normal configuration with the standard pay load a flight path of at least $60 \mathrm{~km}$ can be flown. If sensors are mounted which are lighter than the standard payload, longer flight times can be achieved and even further enlarged by using additional batteries. There will be development in the future that the SONGBIRD can fly around $2 \mathrm{~h}$.

For take-off and landing the engines of the SONGBIRD consume up to $70 \mathrm{~A}$ from a $22.2 \mathrm{~V}$ rechargeable $<$ battery pack. During horizontal flight at a wind speed of $1-2 \mathrm{~m} / \mathrm{s}$ the SONGBIRD consumes 6-8 A. This means that short take-off and landing phases significantly increases the total operation time.

The payload is mounted on a special tray. So the needed sensors (e.g. optical, multi-spectral, hyper-spectral, thermal, gas detection an others) can be changed fast. This follows the philosophy that UAV of the SONGBIRD family should to be professional tools for daily usage. The airframe is built in a combination from glass-fibre and carbon composites, has a life expectancy of more than $800 \mathrm{~h}$ of flight time. Mechanical parts have to be maintained after $300 \mathrm{~h}$ of flight time. This gives the user and customer the possibility to compute the total cost of ownership.

For transport of the SONGBIRD the wing can be dismantled in three parts, so that the box of the SONGBIRD 1500 family member has a size of only $130 \mathrm{~cm}$ x $40 \mathrm{~cm} \times 40 \mathrm{~cm}$. The SONGBIRD 500 fits into a box of $95 \mathrm{~cm} \times 40 \mathrm{~cm} \times 40 \mathrm{~cm}$.
Assembly and disassembly of the SONGBIRDS can be done in less than 10 minutes without special skills or equipment.

For telecommunication different frequencies can be used. The standard implementation is $2.4 \mathrm{GHz}$ for the remote control. The range of the remote control can be enlarged, but the flight controller can operate safely even if the connection to the remote control is lost. So, if the legal requirements are met, beyond line of sight missions can be performed. The communication of flight parameters which include position, speed over ground, air speed, direction, height, battery current, derivation between planned flight and actual flight are transmitted in the 868 or $433 \mathrm{MHz}$ band, to comply with European regulations. Long ranges can be realised either by using higher transmission power and/or more sensitive transmitter and receiver, directional antennas and frequencies are available depending on the specific regulations.

\subsection{Safety features}

To provide a maximum of security, many safety features are implemented. There are two flight controller implemented, most of the sensors controlling the flight are redundant as well. There is a advanced health monitoring system, that failures might be detected before they lead to a loss of the UAV. For example the energy consumption of the engines and servos, the derivation of the respond time of the servos from a reference, the difference between the different speed sensors etc. are recorded and computed (Bethke et al. 2010). So deterioration and wear and tear are detected in an early state, before the component part will fail complete.

As well standard safety features like coming home function in case of low battery power, loss of telecommunication or other mal function is implemented. As well the derivation of the energy consumption of the engines in comparison to the reference representing the flight under no wind, are taken into account. Because the reliability of the UAS is one of the very important features for general application for the UAS in public and private sector so a continuous process of improvement and extension is going on.

\subsection{Examples of the flight properties of the SONGBIRD}

Intensive test flights have been performed under different weather conditions. It turned out that the flight properties of the SONGBIRD are very good.

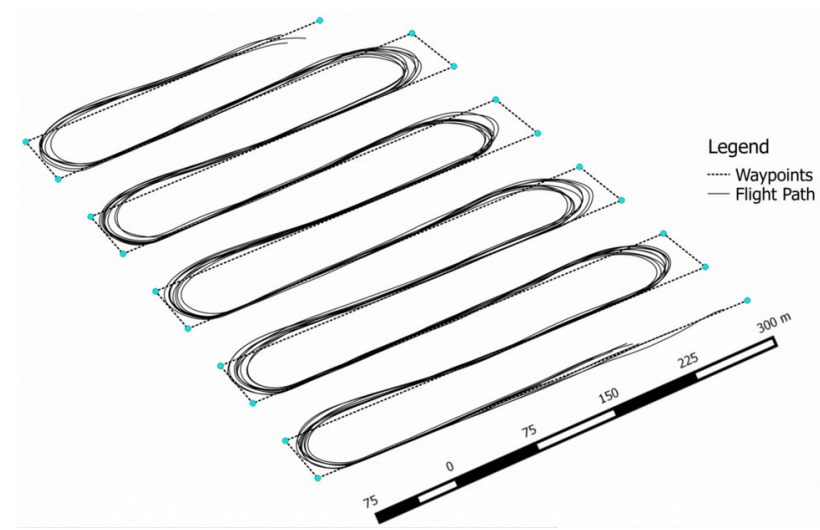

Figure 4. Real flight plan of the SONGBRID $1500 \mathrm{~V} 1$ as flown in May 2015 during strong wind conditions up to $18 \mathrm{~m} / \mathrm{s}$. (Own graph). 
Outstanding is the ability to take off, fly and land under high wind conditions (up to $18 \mathrm{~m} / \mathrm{s}$ ) and the ability of the flight controller / autopilot to reproduce pre determined flight paths.

Figure 4 shows the real flown flight paths at a day with more than $17 \mathrm{~m} / \mathrm{s}$ wind speed. The derivation along the real is just between $3 \mathrm{~m}$ and $6 \mathrm{~m}$. It is only important to give the SONGBIRD some distance after an end of a flight path and turning to adapt to the next flight path.

\subsection{Different versions of the SONGBIRD}

The SONGBIRDs are available in different versions.

There are at the moment two major series. The SONGBIRD 500 with $500 \mathrm{~g}$ nominal pay load has wing span of $2,35 \mathrm{~m}$ and a overall take off weight of less then $5 \mathrm{~kg}$ (see table1).

The SONBIRD 1500 has a nominal pay load of $1,5 \mathrm{~kg}$ and a wing span of $310 \mathrm{~cm}$. In both versions more pay load can be carried, but this reduces the flight time. As well it is possible to carry less pay load, to enlarge the endurance. It planned to create a SONGBIRD 5000 with $5 \mathrm{~kg}$ payload in the future. Interesting is the feature that by the wing profile there is an aerodynamic stability. In the very unlikely case if the stall speed is reached and the mechanism for the vertical landing is not operating, the SONGBIRD should not fall side wards over the wing. It should be come down in the normal flight position.

The main types of SONGBIRD are available in different versions where their equipment is adapted for different applications.

The SONGBIRD-G is for geographical applications (assessing land use land cover, urban dynamics, land resource management, and other more) it has a good optical camera and a normal GPS

\begin{tabular}{|l|c|c|}
\hline & SONGBRID & SONGBRID \\
Span width & 500 & 1500 \\
Nominal payload & $235 \mathrm{~cm}$ & $3.10 \mathrm{~cm}$ \\
Talke off weight with & $500 \mathrm{~g}$ & $1500 \mathrm{~g}$ \\
nominal payload & $4,2 \mathrm{~kg}$ & $7,0 \mathrm{~kg}$ \\
Glide angle & ca. $30: 1$ & ca. $30: 1$ \\
Max speed & ca. $120 \mathrm{~km} / \mathrm{s}$ & ca. $120 \mathrm{~km} / \mathrm{h}$ \\
Standard operation & $55 \mathrm{~km} / \mathrm{h}-$ & $55 \mathrm{~km} / \mathrm{h}-$ \\
speed & $65 \mathrm{~km} / \mathrm{h}$ & $65 \mathrm{~km} / \mathrm{h}$ \\
Max wind speed for & ca. $17 \mathrm{~m} / \mathrm{s}$ & $\mathrm{ca} .18 \mathrm{~m} / \mathrm{s}$ \\
safe operation & $>60 \mathrm{~min}$ & $>60 \mathrm{~min}$ \\
Flight time in standard & & \\
configuration & $95 \mathrm{~cm} \mathrm{x} 35 \mathrm{~cm} \mathrm{x}$ & $130 \mathrm{~cm} \mathrm{x} 40 \mathrm{~cm}$ \\
Transport box & $35 \mathrm{~cm}$ & x $40 \mathrm{~cm}$ \\
Set up time & $<10 \mathrm{~min}$ & $<12 \mathrm{~min}$ \\
VTOL & yes & Yes \\
\hline
\end{tabular}

Table 1. Properties of the first two members of the SONGBIRD family

SONGBIRD-A for agriculture. It comes with a optical and a multi-spectral camera, for estimation of biomass, productivity, detecting pests, malnutrition and diseases. controlling the success of measures like applying fertilisers and spraying pesticides, herbicides and fungicides. As well erosion can be detected. For steering and controlling of irrigation a thermal camera can be used as well.

SONGBRID-S for surveying. In this version a differential GPS and a high quality calibrated camera is used. It is aimed to reach a high precision of the location the post processing. Typical applications are assisting the set up of cadastral land register, surveying for road and railroad planning, precise mapping of erosion on fields and costal erosion. As well for observing building measures, open pit mining and investigation of dykes this version is applied.

SONGBIRD-S+R for search and rescue. This SONGBIRD version has a high quality real time transmission of the video signal of the camera in HD quality if desired. As well one camera is on a gimbal and can be controlled via FPF glasses with eye-tracker. An additional thermal camera for detection of people at night is available, and loud speaker system to communicate with the people on ground can be installed as well (for instance to give information and advices to people in distress e.g. where to go to or how long it take till an ambulance will come).

The SONGBIRD family aims to be complete systems for providing the desired spatial information from the flight planning to the derivation of the wanted information form the remotely sensed information. Therefore additional devices are delivered which are helping to process the remote sensed images and deliver the wanted information in the semantic way and the data format the user needs. For example after landing the flight path and all flight parameters are transferred wireless to a special data station. The images can be transferred and stored to it as well. In the data station the position where the images where taken is automatically written in the EXIF header of the respective images - this increases the speed of the image post processing, for example to compute ortho-photos and ensure the integration of the images in geographical information systems.

The use of special sensors (e.g. gas detectors, particle collectors, meteorological instruments) can be realised in the SONGBRD family. Because the programming of the flight controller is performed in house it can be adapted to the special demands for the customer.

\subsection{Conclusion}

The vertical take off and landing fixed wing SONGBIRD family UAV are very interesting tools for gaining airborne spatial information, because they combine the advantages of multicopter and fixed wing UAV and overcome the disadvantages of the both types. The SONGBRIDS have very good flight properties, are in a wide range independent from wind conditions and can cover large areas. Because they do not need they do not need a landing strip for landing and catapults for take off they are easy and safe to operate. The take off and landing is very smooth so that expensive sensors can be implemented. The SONGBRIDS are easy to be mounted befire flight and dismantled after flight. They can be transported in a comparatively small box. A mature flight controller / autopilot makes the operation easy and numerous safety features and a interesting health care system ensure a high degree of flight safety. The robust construction enables long operation time before maintenance leads to comparatively low total costs of owner ship (TOC).

The SONGBRIDs have proved in be durable tools for professional daily applications. They can contribute to improve the acceptance and general use of UAS. 


\subsection{References}

Bethke, B., Valenti, M., How, J. P. 2010. Experimental demonstration of uav task assignment with integrated health monitoring. IEEE Robotics automation magazine, march.

Cai G., Dias J., Seneviratne L., 2014. A survey of small-scale unmanned aerial vehicles: Recent advances and future development trends. Unmanned Systems, 2(02), 175-199.

Colomina, I., Molina, P., 2014. Unmanned aerial systems for photogrammetry and remote sensing: A review. ISPRS Journal of Photogrammetry and Remote Sensing, 92, 79-97.

Eisenbeiss, H., 2009. UAV Photogrammetry. Dissertation, ETH NO. 18515, Zürich.

Eng, P., Mejias, L., Liu, X., \& Walker, R., 2010. January. Automating human thought processes for a uav forced landing. In Selected papers from the 2nd International Symposium on UAVs, Reno, Nevada, USA June 8-10, 2009, pp. 329-349. Springer Netherlands.

Ferrell P., Smith B., Stark B., YangQuan C., 2013. Dynamic flight modeling of a multi-mode flying wing quadrotor aircraft. In Unmanned Aircraft Systems (ICUAS), in: International Conference on Unmanned Aircraft systems, pages 398-404, doi: 10.1109/ICUAS.2013.6564714.

Gundlach, J., 2012. Designing Unmanned Aircraft Systems: A Comprehensive Approach; American Institute of Aeronautics and Astronautics. Inc.: Reston, VA, USA.

Hartman, P., Martin, 2014: http://www.fsd.rwthaachen.de/English/Research/IMAV.php, revised at the 28.05.2015

Holsten J., Ostermann T., Moormann D., 2011. Design and wind tunnel tests of a tiltwing UAV, in CEAS Aeronautical Journal, Springer Wien, Vol. 2, pp. 69-79.

Hochstenbach, M., Notteboom, C., 2014: Ontwerp en bouw van een onbemand vliegtuig voor autonoom pakkettransport met gecontroleerde transitie van verticaal opstijgen naar voorwaartse vlucht. Master Thesis, KU Leuven.

Hulsman, S., De Groot, J., Dokter, D., 2014. ATMOS UAV; high-tech startup with game-changing ideas. Leonardo Times, 18 (1) 2014.

Kim, H. J., Kim, M., Lim, H., Park, C., Yoon, S., Lee, D., Kim, Y., 2013. Fully autonomous vision-based net-recovery landing system for a fixed-wing uav. Mechatronics, IEEE/ASME Transactions on, 18(4), 1320-1333.

Leomar, P., Tamre, M., Riibe, T., Vaher, T., Haggi, T. 2006. Optimal design and analysis of UAV swan fuselage. In Solid State Phenomena, Vol. 113, pp. 91-96.

Pajares G., 2015. Overview and Current Status of Remote Sensing Applications Based on Unmanned Aerial Vehicles (UAVs). Photogrammetric Engineering \& Remote Sensing, 81(4), pp.281-330.

Sibilski K., Hajduk J., Moldenhower, A., Sibilska, A., 2012. Experimental Validation of Mathematical Model of
Autonomous Gliding Delivery System. 19th AIAA Aerodynamic Decelerator Systems Technology Conference and Seminar.

van Blyenburgh P., 2013. 2013-2014 RPAS Yearbook: Remotely Piloted Aircraft Systems: The Global Perspective, Technical Report. UVS, International. Paris.

Wyllie, T. 2001. Parachute recovery for UAV systems, Aircraft Engineering and Aerospace Technology, Vol. 73 Iss: 6, pp.542 -551 .

Wada, A., Yamashita, T., Maruyama, M., Arai, T., Adachi, H., Tsuji, H. 2015. A surveillance system using small unmanned aerial vehicle (UAV) related technologies. NEC Technical Journal, 8(1), 68-72.

Zang W., Lin J., Wang Y., Tao H., 2012. Investigating smallscale water pollution with UAVR emoteSensingTechnology, IEEE World Automation Congress(WAC),Vol.1 (4),2428,ISBN:978-1-4673-4497-5 